\title{
Control of Water Balance in Infants with Bronchopulmonary Dysplasia: Role of Endogenous Vasopressin
}

\author{
THOMAS A. HAZINSKI, W. ALLEN BLALOCK, AND BARBARA ENGELHARDT \\ Department of Pediatrics, Division of Neonatology, Vanderbilt University School of Medicine, \\ Nashville, Tennessee 37232
}

\begin{abstract}
Babies with chronic bronchopulmonary dysplasia (BPD) can sometimes develop pallor, systemic and pulmonary edema, oliguria, and hyponatremia not attributable to cardiopulmonary or renal impairment. These signs and symptoms might, however, be explained by inappropriate control of vasopressin secretion. To test this hypothesis, we measured plasma vasopressin and osmolality, serum sodium and potassium concentrations, urine output and osmolality, and free water clearance in 26 normoxic infants with BPD aged 1-4 months. All of these infants required supplemental oxygen $\left(\mathrm{FiO}_{2} \mathrm{0.41} \pm 0.03\right.$, mean $\pm 1 \mathrm{SE}$ ) to maintain $\mathrm{O}_{2}$ saturation of $>88 \%$, and six infants also required mechanical ventilation. As controls, 10 infants of similar age but without BPD were also studied. None of the infants had been discharged from the nursery and was receiving any medications, and all were clinically stable when studied. Compared to control infants, infants with BPD had significantly elevated plasma vasopressin concentrations (control $5.2 \pm 0.9 \mathrm{pg} / \mathrm{ml}$; BPD 42.4 \pm 5.1; mean $\pm \mathrm{SE}, p<0.05$ ). Moreover, infants with BPD had hyponatremia and hypotonic plasma, and both urine output and free water clearance were significantly reduced. These data suggest that some infants with chronic BPD have elevated vasopressin levels that are functionally significant. We speculate that excessive stimulation of vasopressin secretion may explain some of the pulmonary and nonpulmonary signs and symptoms in infants with chronic BPD. (Pediatr Res 23: 86-88, 1988)
\end{abstract}

\section{Abbreviations}

BPD, bronchopulmonary dysplasia $\mathrm{ADH}$, antidiuretic hormone

CPAP, continuous positive airway pressure

$\mathrm{FiO}_{2}$, inspired oxygen concentration

$\mathrm{PaCO}_{2}$, arterial $\mathrm{PCO}_{2}$ tension

Babies with chronic BPD can sometimes develop systemic and pulmonary edema, oliguria, hyponatremia, and hypertension that cannot be attributed to chronic congestive heart failure or to renal disease. In some infants with BPD, treatment with diuretics has resulted in improvement in lung function and in systemic edema $(1,2)$. Some of these signs and symptoms are

Received August 3, 1987; accepted September 22, 1987.

Correspondence Thomas A. Hazinski, M.D., Department of Pediatrics, MCN S-4311, Vanderbilt University School of Medicine, Nashville, TN 37232.

Supported in part by a March of Dimes Clinical Research Grant 6-392 and 6499 (TAH). T.A.H. is a recipient of a Career Investigator Award from the American Lung Association. similar to those seen in patients with the syndrome of inappropriate secretion of vasopressin or ADH (3). Although vasopressin is secreted primarily in response to small increases in the osmolality of brain extracellular fluid, it may also be secreted in response to a change in stretch or volume receptor output from the heart, pulmonary veins, and possibly, the chest wall itself (4). Infants with chronic BPD have a reduced functional residual capacity and abnormal lung mechanics $(5,6)$, and vasopressin secretion is increased in other pulmonary diseases where lung mechanics is impaired (7-9). Therefore, we measured the concentration of vasopressin in plasma, the osmolality of plasma and urine, and other indicators of fluid-electrolyte balance to test the hypothesis that infants with BPD have high vasopressin levels that are functionally significant. Although the control of water and electrolyte balance is complex and involves factors other than vasopressin, our data indicate that plasma vasopressin concentrations are elevated in the majority of infants with BPD, and that these elevated concentrations may have important effects on water balance.

\section{MATERIALS AND METHODS}

Study protocol. Thirty-six hospitalized premature infants were the subjects of this study. They were separated into two groups (Table 1). The diagnosis of BPD was made by three criteria: 1) history of respiratory failure at birth which required mechanical ventilation and oxygen therapy, 2) evidence of pulmonary parenchymal disease on a chest radiograph at 28 days of age, and 3) continuous oxygen therapy still necessary beyond age 28 days to maintain $\mathrm{O}_{2}$ saturation at $>88 \%$. As shown in Table 1,26 infants met this criteria and were all oxygen dependent on the day they were studied.

Ten premature infants of similar age but without BPD were also studied as controls. These infants, like the infants with chronic BPD, had never been discharged from the nursery, and were receiving no medications other than vitamins. One control infant was receiving CPAP via nasal prongs and $23 \%$ oxygen for the treatment of apnea of prematurity, but had had no apnea for $72 \mathrm{~h}$ prior to the start of the study.

Infants were eligible for study if they were not receiving antibiotics, diuretics, $\beta$-agonist drugs, or corticosteroids. Infants with BPD were eligible if they had no evidence of deteriorating respiratory status; i.e. if changes in body weight did not exceed $30 \mathrm{~g} / \mathrm{kg} / \mathrm{day}$, and if fluid/electrolyte or oxygen management were unchanged for 2 days before and after the study day. All but three infants received Similac Special Care Formula (Ross Laboratories, Columbus, $\mathrm{OH}), 24 \mathrm{kcal} / \mathrm{oz}$, at rates of $120-150 \mathrm{ml} /$ $\mathrm{kg} /$ day, without other additives or salt supplements. The other three infants (two controls, one infant with BPD) received their mother's breast milk. Intraventricular hemorrhage was identified using the ultrasound technique and graded according to the 
Table 1. Clinical characteristics of 36 study infants (mean \pm 1 SD) is shown*

\begin{tabular}{lcc}
\hline & $\begin{array}{c}\text { Control } \\
(n=10)\end{array}$ & $\begin{array}{c}\text { BPD } \\
(n=26)\end{array}$ \\
\hline Gestational age (wk) & $28 \pm 2$ & $27 \pm 2$ \\
Birth wt (kg) & $0.91 \pm 0.23$ & $0.84 \pm 0.29$ \\
Postnatal age (day) & $42 \pm 12$ & $46 \pm 18$ \\
Body wt $(\mathrm{kg})$ & $1.51 \pm 0.29$ & $1.19 \pm 0.29$ \\
$\mathrm{FiO}_{2}$ & $0.22 \pm 0.1$ & $0.41 \pm 0.14 \dagger$ \\
$\mathrm{Mechanical}$ & $0 / 10$ & $6 / 26 \dagger$ \\
$\mathrm{CPAP}$ only $(n)$ & $1 / 10$ & $3 / 26$ \\
Intraventricular hemorrhage & $4 / 10$ & $7 / 26$ \\
$\geq$ grade III & & \\
$\mathrm{PaCO}_{2}$ (torr) & $37 \pm 3$ & $45 \pm 7$ \\
$\mathrm{PaO}_{2}$ (torr) & $88 \pm 6$ & $90 \pm 4$ \\
\hline
\end{tabular}

* Except for $\mathrm{FiO}_{2}$ and the need for mechanical ventilation, there were no significant differences between the two groups.

$\uparrow$ Significant differences $(p<0.05)$.

criteria of Papile et al. (10). No infant was hypoxemic as assessed by arterial blood gas analysis, transcutaneous $\mathrm{PO}_{2}$ measurement, or oximetry. No infant had clinical evidence of cardiac disease or symptomatic patent ductus arteriosus as evidenced by tachycardia, rales, heart murmur, or cardiomegaly.

Informed consent was obtained from one or both parents and the study was approved by the Committee for the Protection of Human Subjects at Vanderbilt University.

Plasma and urine assays. Infants were supine, and blood samples were collected by venipuncture of an antecubital vein. To minimize possible diurnal variation, all samples were collected between 0800 and $1200 \mathrm{~h}$ on the study day. Vasopressin was measured in duplicate samples of plasma within $72 \mathrm{~h}$ of sample collection. Each specimen was collected in a syringe with citrate as the anticoagulant. These samples were immediately chilled in ice slush and then centrifuged at $2000 \times g$ for $10 \mathrm{~min}$ at $4^{\circ} \mathrm{C}$. Plasma was transferred by pipette to shipping tubes and frozen at $-10^{\circ} \mathrm{C}$, then packed in dry ice for overnight delivery. Samples were assayed using radioimmunoassay by Nichols Institute (San Juan Capistrano, CA).

Plasma and urine osmolality were measured by freezing point depression. Urine samples were screened for glucose using Labstix (Ames, Elkhart, IN); urine samples with any detectable glucose were not analyzed for osmolality. Serum sodium and potassium concentrations were measured by standard ion-selective electrodes in the hospital clinical laboratory. The $\mathrm{PCO}_{2}$ and $\mathrm{PO}_{2}$ were measured in a sample of blood obtained by arterial puncture.

Fluid intake and urine output for the $12 \mathrm{~h}$ before and $12 \mathrm{~h}$ after sample collection were calculated from nursing care records. Urine was collected in preweighed diapers or in standard collection bags taped to the infant's perineum. Body weight was recorded on the morning of sample collection.

Statistical analysis. The clinical criteria of the two groups were compared by unpaired $t$ test or by Fisher's exact test. Variables measured in plasma and urine, body weight, and fluid measurements were compared by parametric or nonparametric tests as appropriate. The relationship between plasma vasopressin concentration and other variables was assessed by simple linear regression (14). The mean $\pm 1 \mathrm{SD}$ are given in tables and text.

\section{RESULTS}

Premature infants with chronic BPD had significantly elevated plasma vasopressin levels when compared to control infants (Table 2). As shown in Table 1, the two groups were similar except for their oxygen requirement and the need for mechanical ventilation in six of the BPD infants. The high vasopressin levels in infants with BPD were not associated with the pressence of either CPAP or intraventricular hemorrhage. The average vasopressin level measured in the six mechanically ventilated BPD infants was $26.7 \pm 6.4 \mathrm{pg} / \mathrm{ml}$; this value did not differ from the group of infants with BPD who were not mechanically ventilated. In infants with BPD, the plasma vasopressin was not related to $\mathrm{PaO}_{2}, \mathrm{PCO}_{2}$, gestational age, or postnatal age.

To determine if these vasopressin levels were functionally significant, we compared plasma and urine osmolality, and serum sodium and potassium concentrations in the two groups (Table 3). Compared to control infants, infants with BPD had significantly lower plasma osmolality, a higher urine osmolality, and a lower serum sodium concentration. These data suggest that the high vasopressin levels were associated with hyponatremia and a plasma osmolality inappropriately low relative to urine osmolality.

To further assess the functional significance of the plasma vasopressin concentration, fluid intake, urine output, and their ratio were compared in the two groups of infants (Table 3). Despite similar fluid, sodium, and potassium intakes, infants with BPD had a significantly lower urine output, and a higher intake/output ratio than control infants had.

Using the variables shown in Table 3 , free water clearance was estimated by calculating the difference between urine output and osmolar clearance with the formula below:

free water clearance $=$ urine output - (urine osmolality $\times$ urine output)/plasma osmolality

The free water clearance of the control infants averaged $45 \pm$ $6 \mathrm{ml} / \mathrm{kg} /$ day, and the free water clearance of the infants with $\mathrm{BPD}$ was $3 \pm 4 \mathrm{ml} / \mathrm{kg} /$ day $(p<0.01)$; this suggests that infants with $\mathrm{BPD}$ and high vasopressin levels have decreased free water clearance.

The six infants with BPD who were receiving mechanical ventilation were indistinguishable from spontaneously breathing $\mathrm{BPD}$ infants with regard to their plasma and urine variables. In the six infants who received mechanical ventilation, plasma vasopressin concentration was not related to peak, mean, or endexpiratory pressures.

\section{DISCUSSION}

We found that some premature infants with chronic BPD have elevated vasopressin concentrations associated with abnormal water balance and hyponatremia. If it is assumed that the normal upper limit for plasma vasopressin concentration can be derived from our control group and is represented by its mean value plus

Table 2. Plasma vasopressin levels in 36 study infants

\begin{tabular}{ccccc}
\hline & & \multicolumn{3}{c}{ Vasopressin $(\mathrm{pg} / \mathrm{ml})$} \\
\cline { 3 - 5 } Study group & $n$ & Mean $+1 \mathrm{SD}$ & Median & Range \\
\hline Control & 10 & $5.2 \pm 2.8$ & 3.6 & $2.8-10.0$ \\
BPD & 26 & $42.4 \pm 34.0^{*}$ & 25.9 & $5.4-80.0$ \\
\hline
\end{tabular}

*Indicates difference from control group, $p<0.05$.

Table 3. Urine and plasma variables measured in study infants (mean $\pm 1 S D$ )

\begin{tabular}{lcc}
\hline & $\begin{array}{c}\text { Control } \\
(n=10)\end{array}$ & $\begin{array}{c}\text { BPD } \\
(n=26)\end{array}$ \\
\hline Plasma osmolality (mosmol/liter) & $286 \pm 21$ & $272 \pm 10^{*}$ \\
Urine osmolality (mosmol/liter) & $114 \pm 60$ & $275 \pm 123^{*}$ \\
Serum sodium (mEq/liter) & $139 \pm 2$ & $132 \pm 4^{*}$ \\
Serum potassium (mEq/liter) & $4.9 \pm 3$ & $5.0 \pm 0.4$ \\
Fluid intake (ml/kg/day) & $134 \pm 15$ & $140 \pm 21$ \\
Urine output (ml/kg/day) & $78 \pm 7$ & $52 \pm 19^{*}$ \\
Intake/output ratio & $1.6 \pm 0.1$ & $2.7 \pm 0.8^{*}$ \\
\hline
\end{tabular}

* Significant difference from control $(p<0.05)$. 
2 SDs above it, then this upper limit would be equal to $10.8 \mathrm{pg} /$ $\mathrm{ml}$. Twenty-one of the $26(80 \%)$ infants with BPD had a vasopressin level above this value. Moreover, although the number of ventilated infants is small, these high levels cannot be explained by the presence of positive airway pressures, or by mechanical ventilation; these factors may increase vasopressin secretion in newborn infants (13-16).

These data extend the observations of Rao et al. (17) who found elevated vasopressin levels in 12 infants with BPD who were rehospitalized for acute severe respiratory failure. In their study, hyponatremia was rare despite high vasopressin levels, suggesting that these acutely sick infants may have been in a nonsteady state in terms of their water balance. As a result, the physiologic importance of the high vasopressin concentrations in more stable infants with chronic BPD was not examined in their report.

Babies with BPD and chronic respiratory distress are characterized by cardiorespiratory instability, and some investigators believe that steady-state measurement of most physiologic functions is impossible in this group of infants. Our criteria for cardiorespiratory stability were strict; we required that waterelectrolyte balance and oxygen therapy be stable for several days before and after the measurement of fluid balance variables.

Although these data suggest a causal link between chronic lung diseases and high vasopressin levels, these two factors cannot be unequivocally correlated because lung function was not measured in all infants and other hormones known to affect fluid and electrolyte balance were not obtained. What are the possible explanations for elevated vasopressin concentrations in babies with chronic BPD? All of these infants were oxygen dependent but not hypoxemic, and all had pulmonary abnormalities visible on the chest radiograph, suggesting that some feature of their chronic lung disease was responsible. Nevertheless, we could not correlate the plasma vasopressin concentration with either $\mathrm{FIO}_{2}$, or the $\mathrm{PO}_{2}$ and $\mathrm{PCO}_{2}$ tension in arterial blood. We did not measure lung mechanics, functional residual capacity, or expiratory flow/volume relationships, and it is possible that these variables may correlate better with vasopressin secretion.

It is possible that these infants with chronic BPD may have had chronic congestive heart failure, which is associated with elevated vasopressin secretion (4). The BPD infants in this study did not have the classic clinical findings of chronic congestive heart failure, and this syndrome is not a common feature of adequately treated chronic BPD. Nevertheless, we cannot rule out the possibility that cardiac dysfunction was present which could not be detected clinically.

Dehydration increases vasopressin secretion but it is unlikely that the infants with BPD were dehydrated, since as shown in Table 3, fluid intake did not differ from that of the control group. Elevated vasopressin levels could also be explained by a central defect of osmotic regulation, as seen in patients with head trauma (15), or in infants with acute intracerebral hemorrhage (16), but intracranial hemorrhage was just as frequent in both groups.

Other explanations for vasopressin excess in these patients might be release of vasopressin from the damaged developing lung or stimulation of vasopressin release by other endogenous stimuli. Vasopressin can be found in pulmonary small cell lung carcinoma of humans (18). In addition, atrial natriuretic factor, hypoxia, undefined stresses, catecholamines, and other factors may also influence vasopressin secretion, but their physiologic effects in patients with chronic lung disease has not yet been reported $(3,4)$.

Although many factors control water and electrolyte balance in humans, only two, vasopressin and atrial natriuretic peptide are secreted due to stimulation of intrathoracic mechanoreceptors $(3,19)$. It is therefore possible that the elevated vasopressin concentrations resulted from abnormal transmural pressure gradients either in the heart, great vessels, or lungs of infants with chronic BPD; this mechanism has been hypothesized by others (6-8) but remains unproven.

In summary, we found that, for reasons yet unknown, some infants with chronic BPD have elevated vasopressin levels, which can cause hyponatremia and oliguria. This abnormality of water balance may explain some of the nonpulmonary signs and symptoms in infants with chronic BPD, and may explain why some infants with chronic BPD can have improved lung function when treated with diuretics $(6,20)$.

\section{REFERENCES}

1. Bancalari E, Abdenour GE, Feller R, Gannon J 1979 Bronchopulmonary dysplasia: clinical presentation. J Pediatr 85:819-823

2. Abman SH, Warady BA, Lum GM, Koops BL 1984 Systemic hypertension in infants with bronchopulmonary dysplasia. J Pediatr 104:929-931

3. Menninger RP 1985 Current concepts of volume receptor regulation of vasopressin release. Fed Proc 44:55-58

4. Robertson GL 1977 The regulation of vasopressin function in health and disease. Recent Prog Horm Res 33:333-374

5. Tepper RS, Morgan WJ, Cota K, Taussig LM 1986 Expiratory flow limitation in infants with bronchopulmonary dysplasia. J Pediatr 109:1040-1046

6. Kao LC, Warburton D, Sargent CW, Platzker ACG, Keens TG 1983 Furosemide acutely decreases airways resistance in chronic bronchopulmonary dysplasia. J Pediatr 103:624

7. Benfield GFA, O'Doherty K, Davies BH 1982 Status asthmaticus and the syndrome of inappropriate secretion of antidiuretic hormone. Thorax 37:147-148

8. Dawson KP, Fergusson DM, West J, Wynne C, Sadler WA 1983 Acute asthma and antidiuretic hormone secretion. Thorax 38:589-591

9. Farber MO, Weinberger MH, Robertson GL, Fineberg NS, Manfredi F 1984 Hormonal abnormalities affecting sodium and water balance in acute respiratory failure due to chronic obstructive lung disease. Chest 85:49-54

10. Papile LA, Burstein J, Burstein R, Koffler H 1980 Incidence and evolution of subependymal and intraventricular hemorrhage: a study of infants with birth weights less than $1500 \mathrm{gm}$. J Pediatr 92:529-534

11. Asher JM, Coates AL, Collinge JM, Milic-Emili J 1982 Measurement of pleural pressure in neonates. J Appl Physiol 52:491-494

12. Zar JH 1974 Biostatistical Analysis. Prentice-Hall, Inc., Englewood Cliffs, NJ

13. Moylan MB, Herrin JT, Krishnamoorthy K, Todres D, Shannon DC 1978 Inappropriate antidiuretic hormone secretion in premature infants with cerebral injury. Am J Dis Child 132:399-402

14. Svenningsen NW, Andreasson B, Lindroth M 1984 Diuresis and urine concentration during CPAP in newborn infants. Acta Paediatr Scan 73:727-732

15. Maroon JC, Campbell RI 1970 Subdural hematoma with inappropriate antidiuretic hormone secretion. Arch Neurol 22:234

16. Richards DE, White RF, Yashon D 1971 Inappropriate release of ADH in subdural hematoma. J Trauma 11:758

17. Rao M, Eid N, Herod L, Parekh A, Steiner P 1986 Antidiuretic hormone response in children with bronchopulmonary dysplasia during episodes of acute respiratory distress Am J Dis Child 140:825-828

18. Becker KL 1984 The endocrine lung. In Becker KL, Gazdar AF (eds) The Endocrine Lung in Health and Disease. W. B. Saunders, Philadelphia, pp 346

19. Manning PT, Schwartz D, Katsube NC, Holmberg SW, Needleman P 1985 Vasopressin-stimulated release of atriopeptin: endocrine antagonists in fluid homeostasis. Science 229:395

20. Engelhardt B, Elliott S, Hazinski TA 1986 Short- and long-term effects of furosemide on lung function in infants with bronchopulmonary dysplasia. J Pediatr 6:1034-1039 